\title{
Consensus on a video analysis framework of descriptors and definitions by the Rugby Union Video Analysis Consensus group
}

\author{
Sharief Hendricks (D) , 1,2,3,4 Kevin Till (D) , 2,3,5,6 Steve den Hollander, ${ }^{1}$ \\ Trevor N Savage (D) , ${ }^{7,8,9}$ Simon P Roberts, ${ }^{10}$ Gregory Tierney, ${ }^{11}$ Nicholas Burger, ${ }^{1}$ \\ Hamish Kerr, ${ }^{12}$ Simon Kemp (D) , ${ }^{13,14}$ Matthew Cross, ${ }^{15}$ Jon Patricios (D) , ${ }^{16,17}$ \\ Andrew J McKune, ${ }^{18,19}$ Mark Bennet, ${ }^{20}$ Andy Rock, ${ }^{21}$ Keith A Stokes (D) , ${ }^{10,13}$ \\ Alex Ross, ${ }^{22}$ Clint Readhead, ${ }^{1,23}$ Kenneth L Quarrie (D) , ${ }^{24}$ Ross Tucker (D) , ${ }^{25}$ \\ Ben Jones $1,2,3,5,6,26,27$
}

- Additional material is published online only. To view please visit the journal online (http://dx.doi.org/10.1136/ bjsports-2019-101293).

For numbered affiliations see end of article.

\section{Correspondence to} Dr Sharief Hendricks, Human Biology, University of Cape Town, Division of Exercise and Sports Medicine, Cape Town, 7700 , South Africa; sharief.hendricks01@gmail.com

Accepted 27 January 2020 Published Online First 20 February 2020

\section{ABSTRACT}

Using an expert consensus-based approach, a rugby union Video Analysis Consensus (RUVAC) group was formed to develop a framework for video analysis research in rugby union. The aim of the framework is to improve the consistency of video analysis work in rugby union and help enhance the overall quality of future research in the sport. To reach consensus, a systematic review and Delphi method study design was used. After a systematic search of the literature, 17 articles were used to develop the final framework that described and defined key actions and events in rugby union (rugby). Thereafter, a group of researchers and practitioners with experience and expertise in rugby video analysis formed the RUVAC group. Each member of the group examined the framework of descriptors and definitions and rated their level of agreement on a 5-point agreement Likert scale (1: strongly disagree; 2: disagree; 3: neither agree or disagree; 4: agree; 5: strongly agree). The mean rating of agreement on the five-point scale (1: strongly disagree; 5: strongly agree) was 4.6 (4.3-4.9), 4.6 (4.44.9), 4.7 (4.5-4.9), 4.8 (4.6-5.0) and 4.8 (4.6-5.0) for the tackle, ruck, scrum, line-out and maul, respectively. The RUVAC group recommends using this consensus as the starting framework when conducting rugby video analysis research. Which variables to use (if not all) depends on the objectives of the study. Furthermore, the intention of this consensus is to help integrate video data with other data (eg, injury surveillance).

\section{INTRODUCTION}

Video analysis in sport is the systematic observation and interpretation of video to improve objectivity and reduce the bias and subjectivity that are inherent in human observation. ${ }^{1}$ It is a branch of the sports science subdiscipline known as performance analysis that merges qualitative biomechanical methods and notational analysis. ${ }^{23}$ Arguably, an unintended consequence of the link between performance analysis and video analysis is that most analyses have a performance-orientated focus.

While the utility of video analysis beyond the scope of performance has been recognised before, ${ }^{4-6}$ its role in understanding injury mechanisms and risk factors, and assisting medical protocols (eg, head injury assessment $)^{7}$ and referee decision making (eg, television match official reviewing dangerous play) in rugby has grown over the last 10 years. This growth has precipitated the need for us to rethink video analysis as a predominantly performance-focused subject. In most team settings and within national and international rugby organisations, routine video analysis work falls within the coaching/performance department, without necessarily satisfying the needs of the medical department in terms of understanding injury mechanisms, risk factors and assisting with medical decision making.

An important methodological aspect of video analysis is to clearly describe and define actions and events to reduce bias and improve reliability. ${ }^{9} 10$ Despite this, den Hollander et $a l^{11}$ found that half of all video analysis studies in rugby did not provide clear, detailed descriptions and definitions, while those that did differed in how they defined certain actions and events, limiting opportunities to make interstudy comparisons. For example, some studies use the World Rugby (formerly the International Rugby Board) law definition of the tackle, which requires the player with the ball (ball-carrier) to go to ground before a tackle can be observed, while other studies defined the tackle as 'any attempt to stop or impede the ball-carrier, irrespective of whether or not the ball-carrier was brought to ground' ${ }^{12-16}$ For the field to evolve and become more integrated, a framework with clear descriptions and definitions of key actions and events needs to be developed. To address the above-mentioned concerns, the rugby union Video Analysis Consensus (RUVAC) group was formed to synthesise a framework of descriptors and definitions to improve the consistency and quality of video analysis work in rugby union.

\section{METHODS}

A two-step process was used to develop the framework of descriptors and definitions and reach consensus. For step 1, we performed a systematic search of the literature using the methods described by den Hollander et al. ${ }^{11}$ Specific search terms were used to identify peer-reviewed articles in three electronic databases: Scopus, PubMed and Web of Science. The search terms were 'rugby union' in the 
title, keywords or abstracts linked with any of the following terms: 'performance analysis', 'video analysis,' 'tackle performance', 'video', 'notational analysis', 'match performance', 'match analysis', 'time motion analysis', 'attacking strategies', 'defensive strategies', 'performance indicators', 'injury risk', 'injury mechanisms' or 'injury rates' anywhere in the text. Each of these terms were searched separately with 'rugby union' either in the title, keywords or abstracts (a total of 14 searches for each database). For example, in Scopus, the full electronic search strategy for the term 'video analysis' was: (TITLE-ABS-KEY("Rugby Union") AND ALL ("video analysis")) AND PUBYEAR <2019 AND (LIMIT-TO (LANGUAGE, “English”)) AND (LIMIT-TO (SRCTYPE, “j”)). The results of all 14 searches were subsequently merged and duplicates removed. The time frame for the literature search was any study published up to 31 December 2018. The inclusion criteria were as follows: the article needed to use video analysis to study rugby union match footage and needed to be published in English and in a peer-reviewed journal. Inclusion criteria were applied at the title, abstract and full-text level, and any article not meeting the criteria was omitted from the review. The results from all three databases were merged, and duplicates were removed. Thereafter, a second reviewer applied the inclusion criteria to the title, abstract and full-text level. Any discrepancies between reviewer 1 and reviewer 2 were discussed and included/excluded from the final database. From this systematic search, papers that provided descriptors and definitions were identified. Only published papers that used video and provided descriptors and definitions of key contact events and outcomes were selected. If the same or similar descriptors and definitions were found in multiple papers, the original paper that provided the definition was cited. In addition to this, a meeting was held to discuss what descriptors are important for each contact event.

For step 2, a prominent group of researchers and practitioners with experience and expertise in all rugby video analysis objectives (performance, injury, medical/referee decision making and physical demands) collaborated to form the RUVAC group. No formal process was used to convene the group; however, consideration was given to having different national Unions represented. Once the group was formed, consensus on the descriptors

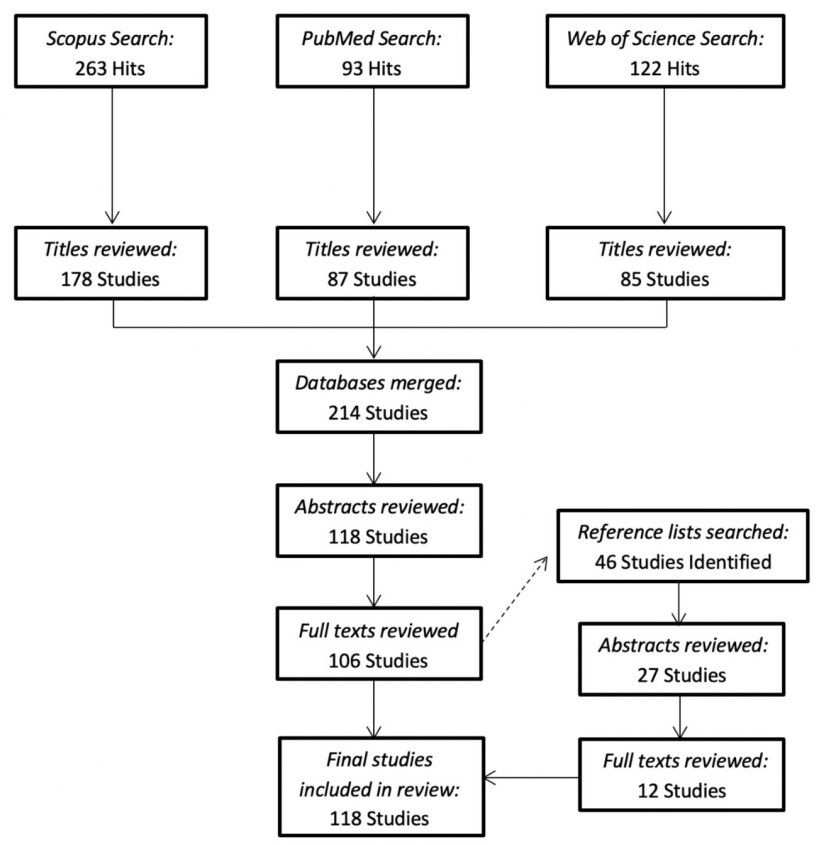

Figure 1 Flow diagram of literature search. and definitions developed in step 1 was attained using a Delphi consensus method. ${ }^{17} 18$ This method required each member to examine the framework of descriptors and definitions and rate their level of agreement on a 5-point agreement Likert scale (1: strongly disagree; 2: disagree; 3: neither agree or disagree; 4: agree; 5: strongly agree). Agreement ratings were obtained separately for each contact event: the match characteristics, the tackle technique scoring criteria and the video analysis tackle model. For each of these, the mean agreement $( \pm 95 \% \mathrm{CI})$ was calculated by summing all the ratings and dividing it by the total number of respondents. After the first round of ratings, some comments and suggestions were proposed. Accordingly, these comments and suggestions were added, and a second round of ratings were obtained based on the revised descriptors and definitions. The level of agreement after round $2(n=17)$ for each contact event, the match characteristics, the tackle technique scoring criteria and the video analysis tackle model are reported in the results section.

\section{RESULTS}

A total of 118 articles on video analysis in rugby matches have been published up to 31 December 2018 (figure 1). Fifty-five per cent $(n=60)$ of these studies provided definitions. Seventeen articles were used to develop the final framework of descriptors and definitions and the technique criteria for the front-on tackle (tables 1-5 and online supplementary appendix 1 and 2) ${ }^{13-1619-31}$

The mean rating of agreement was 4.6 (4.3-4.9), 4.6 (4.44.9), $4.7(4.5-4.9), 4.8(4.6-5.0)$ and $4.8(4.6-5.0)$ for the tackle, ruck, scrum, line-out and maul, respectively. For match characteristics, the tackle technique criteria and tackle video analysis model (figure 2), the mean rating of agreement was 4.6 (4.4-4.9), 4.5 (4.2-4.9) and 4.2 (3.9-4.7), respectively.

\section{DISCUSSION}

The aim of this consensus is to improve the consistency and quality of video analysis work in rugby union. This list of descriptors and definitions was designed based on the deterministic and phase analysis models ${ }^{15}{ }^{33-35}$ with the intention of being comprehensive, focusing on key actions and versatile across video analysis objectives. Therefore, the RUVAC group recommends using these descriptors and definitions as the starting framework when conducting rugby video analysis research. Which variables to use (if not all) depends on the objectives of the study. For example, if it is a tackle-related study, only the tackle variables may apply. Also, which variables are ultimately captured and analysed depends on the frequency of occurrence of that action in the sample. Furthermore, although comprehensive, the list is finite, and variables can also be added to meet the objectives of the study. For instance, to describe concussion injury mechanism using video analysis, Hendricks et a $l^{30}$ studied descriptors specific to concussion, such as 'acceleration of the head'. It is also recommended that video analysis projects using one analyst should be tested for intra-rater reliability and, if possible, inter-rater reliability as well. In cases where more than one analyst is used, testing inter-rater reliability is essential. Using video to observe body positions and actions is challenging, and reliability across the descriptors will differ. ${ }^{15}$ It may be difficult to achieve an acceptable level of reliability on the first round. However, reliability testing for a video analysis project should be considered a process. If an acceptable intrarater or inter-rater reliability was not attained during the first round of testing, improvements can be made by engaging the rater(s) to discuss and clarify any analysis issues. ${ }^{14} 15$

\section{Integration with additional data sources}

Information from external data sources, for example, injury surveillance data, wearable technology and so on should be 
Consensus statement

\begin{tabular}{|c|c|c|c|}
\hline Descriptor & Definitions & Descriptor & Definitions \\
\hline Tackle Event ${ }^{13-16}$ & $\begin{array}{l}\text { An event where one or more tacklers (player or players making the tackle) attempted to stop } \\
\text { or impede the ball-carrier (player carrying the ball) whether or not the ball-carrier was brought } \\
\text { to ground. }\end{array}$ & \multirow[t]{4}{*}{ Type of illegal tackle } & \multirow{4}{*}{$\begin{array}{l}\text { High tackle: a dangerous, high tackle indicated by the referee. } \\
\text { Stiff-arm tackle: a dangerous stiff-arm tackle as indicated by the referee. } \\
\text { Shoulder charge: a dangerous use of the shoulder to impede the ball-carrier without } \\
\text { attempting to grasp that player. } \\
\text { Lift tackle: tackler raises ball-carrier's hips above ball-carrier's head. } \\
\text { Collision (no-arm) tackle: tackler impedes ball-carrier without the use of the arms. } \\
\text { Aerial collision: player is tackled while both feet are off the ground. } \\
\text { Late tackle after the whistle: a ackle after the referee whistle has stopped play. } \\
\text { Late tackle after the ball is played: a tackle after the attacking player has passed or kicked } \\
\text { the ball. } \\
\text { Tackle without the ball: an attacking player, not in possession of the ball, is impeded/tackled }\end{array}$} \\
\hline Frequency of tackle & Count of tackle events during match play. & & \\
\hline Tackle context & & & \\
\hline \multirow[t]{2}{*}{$\begin{array}{l}\text { Set piece event or phase } \\
\text { event before tackle event }\end{array}$} & \multirow{2}{*}{$\begin{array}{l}\text { Ruck. } \\
\text { Lineout. } \\
\text { Maul. } \\
\text { Scrum. } \\
\text { Kick-off. } \\
\text { Kick in play. }\end{array}$} & & \\
\hline & & \multirow[t]{3}{*}{ Active or passive ${ }^{16}$} & \multirow{3}{*}{$\begin{array}{l}\text { If a shoulder tackle, was it active or passive } \\
\text { Active shoulder tackle: first contact is with the tackler's shoulder, and the tackler drives or } \\
\text { attempts to drive the ball-carrier backwards. } \\
\text { Passive shoulder tackle: first contact is with the tackler's shoulder, and the tackler does not } \\
\text { drive or attempts to drive the ball-carrier backwards. }\end{array}$} \\
\hline $\begin{array}{l}\text { Number of phases before } \\
\text { tackle event }\end{array}$ & Number of phases from the restart to the tackle. & & \\
\hline \multirow{2}{*}{$\begin{array}{l}\text { Total number of passes from } \\
\text { the last event (ruck, lineout, } \\
\text { maul, scrum and kick-off) }\end{array}$} & \multirow{2}{*}{$\begin{array}{l}\text { Count of passes (number of times the ball is transferred between attacking players) from the } \\
\text { last event (ruck, lineout, maul, scrum and kickoff) leading up to the tackle. }\end{array}$} & & \\
\hline & & \multirow[t]{2}{*}{ Direction of contact ${ }^{13-15}$} & \multirow{2}{*}{$\begin{array}{l}\text { Front-on: tackler makes contact with the front of the ball-carrier. } \\
\text { Side-on: tackler makes contact with the ball-carrier's side. } \\
\text { Behind: tackler makes contact with the ball-carrier's from behind. }\end{array}$} \\
\hline Defender & Player/s involved in the tackle on the defending team. & & \\
\hline \multicolumn{2}{|l|}{$\begin{array}{l}\text { Precontact }(1 \mathrm{~s} \text { before } \\
\text { contact) }\end{array}$} & Number of tacklers & $\begin{array}{l}\text { Number of defenders actively attempting to stop or impede the ball-carrier (player carrying the } \\
\text { ball) whether the ball-carrier was brought to ground. Tacklers are counted until the ball-carrier } \\
\text { is brought to ground. }\end{array}$ \\
\hline $\begin{array}{l}\text { Positional grouping of } \\
\text { tackler }^{2125}\end{array}$ & $\begin{array}{l}\text { Tight forwards: loosehead and tighthead prop, hooker and second row. } \\
\text { Loose forwards: open-side and blind-side flankers and number } 8 . \\
\text { Inside backs: scrum-half, fly-half and inside centre. } \\
\text { Outside backs: outside centre, both wings and fullback. }\end{array}$ & \multirow{2}{*}{$\begin{array}{l}\text { Tackle sequence (additional } \\
\text { defender(s) must join while } \\
\text { tackle is still in progress, } \\
\text { before the ruck begins) }^{14} 1521\end{array}$} & \multirow{2}{*}{$\begin{array}{l}\text { One-on-one: one defender contacts one attacker. } \\
\text { Sequential: one defender contacts one attacker, followed by a second defender joining the } \\
\text { contact situation. (can be coded as a separate tackle) } \\
\text { Simultaneous: two defenders contact one attacker at the same time (coded as separate } \\
\text { tackles) } \\
\text { Dual sequential: two defenders contact one attacker followed by a third/fourth defender } \\
\text { joining the contact situation. (coded as separate tackles). }\end{array}$} \\
\hline $\begin{array}{l}\text { Body position at } 1 \mathrm{~s} \text { before } \\
\text { contact }^{212931}\end{array}$ & $\begin{array}{l}\text { Upright: tackler displayed high body height with knees extended and hips neutral/extended. } \\
\text { Medium: tackler displayed moderate flexion at knees and hips. } \\
\text { Low: tackler displayed low body height. }\end{array}$ & & \\
\hline \multirow{2}{*}{$\begin{array}{l}\text { Body position at } 0.5 \mathrm{~s} \text { before } \\
\text { contact }^{212931}\end{array}$} & \multirow{2}{*}{$\begin{array}{l}\text { Upright: tackler displayed high body height with knees extended and hips extended. } \\
\text { Medium: tackler displayed moderate flexion at knees and hips. } \\
\text { Low: tackler displayed low body height. }\end{array}$} & \multicolumn{2}{|l|}{ Postcontact } \\
\hline & & \multirow[t]{2}{*}{$\begin{array}{l}\text { Tackler leg drive after } \\
\text { contact }^{212325}\end{array}$} & \multirow{2}{*}{$\begin{array}{l}\text { Absent: no leg drive. } \\
\text { Moderate: moderate knee movement, with no high lift. } \\
\text { Strong: high, rapid knee lift. }\end{array}$} \\
\hline \multirow{2}{*}{$\begin{array}{l}\text { Head position before } \\
\text { contact }^{212329-31}\end{array}$} & \multirow{2}{*}{$\begin{array}{l}\text { Up and forward: gaze focused on ball-carrier. } \\
\text { Away: gaze away from ball-carrier. } \\
\text { Down: gaze pointing towards the ground (and not the ball-carrier). } \\
\text { Motion/Tracking: tackler's gaze was not fixed (head was moving) in an attempt to follow the } \\
\text { ball-carrier through the field of play. }\end{array}$} & & \\
\hline & & $\begin{array}{l}\text { Upper body usage after } \\
\text { contact }^{231}\end{array}$ & $\begin{array}{l}\text { Yes: tackler uses upper body (arms, shoulders) to actively pull/wrap/wrestle ball-carrier after } \\
\text { contact. } \\
\text { No: no active upper body (arms and shoulders) usage after contact. }\end{array}$ \\
\hline \multirow[t]{2}{*}{ Speed of tackler ${ }^{13-1521}$} & \multirow{2}{*}{$\begin{array}{l}\text { Fast: running or sprinting - purposeful running with maximal effort, with high knee lift. } \\
\text { Moderate: jogging - non-purposeful slow running with low knee lift. } \\
\text { Slow: stationary or walking, or no visible rapid foot movement. }\end{array}$} & Jackal & $\begin{array}{l}\text { A defender competes for the ball using their hands after a tackle was made but before a ruck } \\
\text { is formed. }\end{array}$ \\
\hline & & Attacker & Player/s involved in the tackle on the attacking team. \\
\hline $\begin{array}{l}\text { Anticipation-whether } \\
\text { the player was aware of } \\
\text { impending contact situation }\end{array}$ & $\begin{array}{l}\text { Yes: player was aware of/attuned to impending contact. } \\
\text { No: player was unaware of/oblivious to impending contact. }\end{array}$ & $\begin{array}{l}\text { Precontact }(0.5 \mathrm{~s} \text { before } \\
\text { contact) }\end{array}$ & \\
\hline \multicolumn{2}{|l|}{ Contact } & \multirow{2}{*}{$\begin{array}{l}\text { Positional grouping of ball- } \\
\text { carrier }^{2125}\end{array}$} & \multirow{2}{*}{$\begin{array}{l}\text { Tight forwards: loosehead and tighthead prop, hooker and second row. } \\
\text { Loose forwards: open-side and blind-side flankers number } 8 . \\
\text { Inside backs: scrum-half, fly-half and inside centre. } \\
\text { Outside backs: outside centre, both wings and fullback. }\end{array}$} \\
\hline \multirow{3}{*}{$\begin{array}{l}\text { First point of contact on the } \\
\text { ball-carrier (ie, where on the } \\
\text { ball-carrier is contacted? })^{13-15}\end{array}$} & \multirow{3}{*}{$\begin{array}{l}\text { Lower leg: area below the knee. } \\
\text { Hip: on the short's line. } \\
\text { Upper leg: area between the hips (shorts line) and the knees. } \\
\text { Torso: above the ball-carrier's hip level (shorts line) to the level of the ball-carrier's arm pit. } \\
\text { Shoulder: from the ball-carrier's arm pit level to the shoulder. } \\
\text { Arm: below the ball-carrier's arm pit level but not making contact on the body (contact only to } \\
\text { the arm of the ball-carrier without any contact to their torso). } \\
\text { Head and neck: above the shoulder (shirt/neck) with any connection with the head/neck } \\
\text { during the course of the tackle. } \\
\text { For all of the above, left or right side. }\end{array}$} & & \\
\hline & & $\begin{array}{l}\text { Body position at } 1 \mathrm{~s} \text { before } \\
\text { contact }^{12} 12931\end{array}$ & $\begin{array}{l}\text { Upright: ball-carrier displayed high body height with knees extended and hips neutral/ } \\
\text { extended. } \\
\text { Medium: ball-carrier displayed moderate flexion at knees and hips. } \\
\text { Low: ball-carrier displayed low body height. }\end{array}$ \\
\hline & & $\begin{array}{l}\text { Body position at } 0.5 \mathrm{~s} \text { before } \\
\text { contact }^{212931}\end{array}$ & $\begin{array}{l}\text { Upright: ball-carrier displayed high body height with knees extended and hips extended. } \\
\text { Medium: ball-carrier displayed moderate flexion at knees and hips. } \\
\text { Low: ball-carrier displayed low body height. }\end{array}$ \\
\hline \multirow[t]{2}{*}{$\begin{array}{l}\text { Tackler body position at } \\
\text { contact }\end{array}$} & \multirow{2}{*}{$\begin{array}{l}\text { Upright: the tackler is standing in an upright position, with the knees only slightly bent and } \\
\text { with minimal hip flexion (when the tackler's chest is presented to the ball-carrier at contact). } \\
\text { Bent at the waist: the tackler is bent at the waist or crouched (where the tackler presents the } \\
\text { top of the shoulder to the ball-carrier or upper body is perpendicular to the ground). } \\
\text { Falling/diving: the tackler is in the process of falling or diving to ground at the point of } \\
\text { contact. }\end{array}$} & $\begin{array}{l}\text { Head position before } \\
\text { contact }^{212329-31}\end{array}$ & $\begin{array}{l}\text { Up and forward: gaze focused on tackler. } \\
\text { Away: gaze away from tackler. } \\
\text { Down: gaze pointing towards the ground (and not the tackler). } \\
\text { Motion/tracking: ball-carrier's gaze was not fixed (head was moving). }\end{array}$ \\
\hline & & $\begin{array}{l}\text { Distance from tackler at ball } \\
\text { reception }^{142126}\end{array}$ & $\begin{array}{l}\text { Near: less than } 2 \mathrm{~m} \text { of the tackler. } \\
\text { Moderate: between } 2 \mathrm{~m} \text { and } 4 \mathrm{~m} \text { of the tackler. }\end{array}$ \\
\hline \multirow{4}{*}{$\begin{array}{l}\text { Was there contact between } \\
\text { the tackler's head and ball- } \\
\text { carrier's body (Y/N)? (that } \\
\text { is, where does the tackler's } \\
\text { head go?) }\end{array}$} & \multirow{4}{*}{$\begin{array}{l}\text { Yes or no } \\
\text { If yes, location: } \\
\text { Head to head. } \\
\text { Head to shoulder. } \\
\text { Head to arm. } \\
\text { Head to torso. } \\
\text { Head to hip. } \\
\text { Head to upper leg. } \\
\text { Head to knee. } \\
\text { Head to lower leg. } \\
\text { Head to ground. } \\
\text { Head to equipment. } \\
\text { Whiplash injury. } \\
\text { Head-to-head teammate. }\end{array}$} & & Distant: greater than $4 \mathrm{~m}$ from the tackler. \\
\hline & & $\begin{array}{l}\text { Pattern of running prior to } \\
\text { contact }^{2126}\end{array}$ & $\begin{array}{l}\text { Straight: ball-carrier ran straight at the defence. } \\
\text { Side step: ball-carrier performed an evasive step initiated by either leg before contact. } \\
\text { Arcing run: ball-carrier performed arcing run. } \\
\text { Lateral run: ball-carrier performed a run from touchline to touchline. } \\
\text { Diagonal run: ball-carrier runs at an angle, instead of straight at the tackler. }\end{array}$ \\
\hline & & Speed of ball-carrier ${ }^{13-15} 21$ & $\begin{array}{l}\text { Fast: running or sprinting - purposeful running with maximal effort, with high knee lift. } \\
\text { Moderate: jogging - non-purposeful slow running with low knee lift. } \\
\text { Slow: stationary or walking - no visible rapid foot movement. }\end{array}$ \\
\hline & & $\begin{array}{l}\text { Anticipation - whether } \\
\text { the player was aware of } \\
\text { impending contact situation }\end{array}$ & $\begin{array}{l}\text { Yes: player was aware of/attuned to impending contact. } \\
\text { No: player was unaware of/oblivious to impending contact. }\end{array}$ \\
\hline
\end{tabular}




\begin{tabular}{|c|c|}
\hline Descriptor & Definitions \\
\hline $\begin{array}{l}\text { Was there contact between } \\
\text { the ball-carrier's head and } \\
\text { tackler's body (Y/N)? (ie, } \\
\text { where does the ball-carrier's } \\
\text { head go?) }\end{array}$ & $\begin{array}{l}\text { Yes or no } \\
\text { If yes, location: } \\
\text { Head to head. } \\
\text { Head to shoulder. } \\
\text { Head to arm. } \\
\text { Head to torso. } \\
\text { Head to hip. } \\
\text { Head to upper leg. } \\
\text { Head to knee. } \\
\text { Head to lower leg. } \\
\text { Head to ground. } \\
\text { Head to equipment. } \\
\text { Whiplash injury. } \\
\text { Head-to-head teammate. } \\
\text { For all of the above, left or right side. } \\
\text { If no, tackler's body the BC's head was in closest proximity to: } \\
\text { Head to shoulder. } \\
\text { Head to arm. } \\
\text { Head to torso. } \\
\text { Head to hip. } \\
\text { Head to upper leg. } \\
\text { Head to knee. } \\
\text { Head to lower leg. } \\
\text { Head to ground. } \\
\text { Head to equipment. } \\
\text { Whiplash injury. } \\
\text { Head-to-head teammate. } \\
\text { For all of the above, left or right side. }\end{array}$ \\
\hline Fend ${ }^{162126}$ & $\begin{array}{l}\text { Absent: ball-carrier provided no fend. } \\
\text { Moderate: ball-carrier provided a light to moderate fend (eg, swat or slap technique). } \\
\text { Strong: ball-carrier provided strong fend (eg, push technique). }\end{array}$ \\
\hline Contact impact intensity $^{14-16}$ & $\begin{array}{l}\text { Subjective description of physical impact between the ball-carrier and tackler: } \\
\text { Low. } \\
\text { Medium. } \\
\text { High. }\end{array}$ \\
\hline $\begin{array}{l}\text { Attacker sequence (additional } \\
\text { attacker(s) must join while } \\
\text { tackle is still in progress, } \\
\text { before the ruck begins) }{ }^{1430}\end{array}$ & $\begin{array}{l}\text { One-on-one: one defender contacts one attacker. } \\
\text { Sequential: one attacker contacts one defender, followed by a second attacker joining the } \\
\text { contact situation. } \\
\text { Simultaneous: two attackers contact one defender at the same time. } \\
\text { Dual sequential: two attackers contacts one defender followed by a third/fourth attacker } \\
\text { joining the contact situation. }\end{array}$ \\
\hline $\begin{array}{l}\text { Attacker body position at } \\
\text { contact }\end{array}$ & $\begin{array}{l}\text { Upright: the ball-carrier is standing in an upright position, with the knees only slightly bent } \\
\text { and with minimal hip flexion (when the ball-carrier's chest is presented to the tackler at } \\
\text { contact). } \\
\text { Bent at the waist: the ball-carrier is bent at the waist or crouched (where the ball-carrier } \\
\text { presents the top of the shoulder to the tackler, or upper body is perpendicular to the ground). } \\
\text { Falling/diving: the BC is in the process of falling or diving to ground at the point of contact. }\end{array}$ \\
\hline $\begin{array}{l}\text { Ball-carrier leg drive after } \\
\text { contact }^{212325}\end{array}$ & $\begin{array}{l}\text { Absent: no leg drive. } \\
\text { Moderate: Moderate knee movement, with no high lift. } \\
\text { Strong: high, rapid knee lift. }\end{array}$ \\
\hline $\begin{array}{l}\text { Upper body usage after } \\
\text { contact }\end{array}$ & $\begin{array}{l}\text { Yes: ball-carrier uses upper body (arms and shoulders) to actively wrestle/push the tackler } \\
\text { after contact. } \\
\text { No: no active upper body (arms and shoulders) usage after contact. }\end{array}$ \\
\hline Tackle result ${ }^{212327}$ & $\begin{array}{l}\text { Offload: the ball-carrier is able to pass the ball to a teammate during the tackle. } \\
\text { Tackle break: the ball-carrier successfully penetrates the attempted tackle and continues to } \\
\text { advance. } \\
\text { Tackle completed: when an offload or tackle break does not occur, and either player goes to } \\
\text { ground or the ball-carrier is held up and cannot progress further. This can also be considered } \\
\text { a successul tackle. } \\
\text { Ruck formed: a phase of play whereby one or more players from each team, who are on their } \\
\text { feet, in physical contact, close around the ball on the ground. } \\
\text { Possession lost: the attacking team is unable to advance through an offload or tackle break, } \\
\text { or form a ruck, and lose the ball either through an infringement or error. }\end{array}$ \\
\hline $\begin{array}{l}\text { Which player achieves contact } \\
\text { territorial dominance? } ?^{2123}\end{array}$ & $\begin{array}{l}\text { The direction of progression the tackler and ball-carrier made (as a single unit) towards the } \\
\text { opposition try-line from the point of contact to the point where both players went to ground } \\
\text { (completed tackle) or when a maul is formed. This is considered an indication of the physical } \\
\text { dominance of the tackler or ball-carrier in the contact. } \\
\text { Ball-carrier. } \\
\text { Tackler. } \\
\text { No change. }\end{array}$ \\
\hline Infringements & $\begin{array}{l}\text { Penalty awarded against defender. } \\
\text { Penalty awarded against attacker. } \\
\text { Infringement acknowledged by referee - advantage used by defending team. } \\
\text { Infringement acknowledged by referee - advantage used by attacking team. } \\
\text { (Reason for infringement can also be captured). }\end{array}$ \\
\hline Injury & $\begin{array}{l}\text { Medical attention: player received medical attention and either continued playing or was } \\
\text { removed permanently or temporarily. } \\
\text { No medical attention: coder observed a possible injury to a player, but said player did not } \\
\text { receive medical attention during the match. } \\
\text { Was the player removed from play?: yes/no. } \\
\text { Possible head injury?: yes/no. } \\
\text { `For professional level only* Was a head injury assessment instigated? } \\
\text { Yes/no. } \\
\text { Did the player return to play?: yes/no. }\end{array}$ \\
\hline Injured player & $\begin{array}{l}\text { Ball-carrier. } \\
\text { Tackler. } \\
\text { Not clear. }\end{array}$ \\
\hline Injury location & $\begin{array}{l}\text { Lower leg: area below the knee. } \\
\text { Hip: on the short's line. } \\
\text { Upper leg: area between the hips (short line) and the knees. } \\
\text { Torso: above the ball-carrier's hip level (short line) to the level of the ball-carrier's arm pit. } \\
\text { Shoulder: from the ball-carrier's arm pit level to the shoulder. } \\
\text { Arm: below the ball-carrier's arm pit level. } \\
\text { Head and neck: above the shoulder (shirtneck). } \\
\text { When an injury is observed the injurious event should recorded and linked to injury surveillance } \\
\text { data. } \\
\text { Injury location: } \\
\text { Head and neck. } \\
\text { Upper extremity (shoulders and arms). } \\
\text { Lower extremity (legs). } \\
\text { Torso. } \\
\text { Unknown location. }\end{array}$ \\
\hline
\end{tabular}

Table 2 Ruck descriptors and definitions

\begin{tabular}{ll}
\hline Descriptor & Definitions \\
\hline Ruck $^{28}$ & $\begin{array}{l}\text { A ruck is formed when at least one player from each team is in contact, on their } \\
\text { feet and over the ball, which is on the ground. Once a ruck is formed, additional } \\
\text { players joining the ruck to compete for the ball, without being guilty of foul play, are } \\
\text { considered rucking. }\end{array}$ \\
$\begin{array}{l}\text { Frequency of ruck } \\
\text { Defender }\end{array}$ & $\begin{array}{l}\text { Count of ruck events during match play. } \\
\text { How did the ruck start }\end{array}$ \\
$\begin{array}{l}\text { Tackle. } \\
\text { Maul. } \\
\text { Lineout. }\end{array}$ \\
Speed of entry into ruck & $\begin{array}{l}\text { Fast: Running or sprinting - purposeful running with maximal effort, with high } \\
\text { knee lift. } \\
\text { Moderate: Jogging - non-purposeful slow running with low knee lift. } \\
\text { Slow: stationary or walking, or no visible foot movement. }\end{array}$ \\
Time in ruck & $\begin{array}{l}\text { Duration (in minutes:seconds) from when the ruck has formed to when the ball is } \\
\text { available to be played. }\end{array}$ \\
Activity at the ruck & $\begin{array}{l}\text { No pressure: defenders are not actively attempting to regain possession. } \\
\text { Early counter ruck: defenders compete for the ball without the use of their hands } \\
\text { before attackers had secured possession. } \\
\text { Late counter ruck: defenders compete for the ball without the use of their hands } \\
\text { after attackers had secured possession. }\end{array}$
\end{tabular}

Attacker

Number of attackers in ruck Count of attackers actively engaged in ruck.

Speed of entry into ruck Fast: running or sprinting, purposeful running with maximal effort, with high knee lift. Moderate: jogging, non-purposeful slow running with low knee lift. Slow: stationary or walking - no visible foot movement.

Ruck arrival $^{23} \quad$ Early: ball-carrier's teammates are first to arrive and engage in the ruck. Late: tackler's teammates are first to arrive and engage in the ruck.

Activity at the ruck ${ }^{2327}$ Clearing: attackers are actively pushing and/or driving opponents off the ball, either on their own or binding to team members.

Protecting the ball: attackers are positioned over the ball to prevent access to the opponents.

In sequence, a combination of clearing and protecting: attackers actively clear the ruck first, before protecting the ball.

In sequence, a combination of protecting and clearing: attackers actively protect the ball first, before clearing the ruck.

Ball-carrier falling direction ${ }^{23}$ Forward: ball-carrier falls with the ball positioned between the ball-carrier and the opposition's try-line.

Sideward: ball-carrier falls with the ball positioned between the ball-carrier and either side-line.

Backward: ball-carrier falls with the ball positioned between the ball-carrier and their own try-line.

Active ball placement ${ }^{23} \quad$ Yes: ball-carrier actively placed the ball after going to the ground to continue play. No: ball-carrier fails to actively place the ball after going to the ground to continue play.

Ruck outcomes

Ruck result ${ }^{2327} \quad$ Attacker retains the ball: attacking team maintains possession of the ball after the ruck contest and the ball is made available to be played.

Defender gains the ball: attacking team fails to maintain possession of the ball Defender gains the

Ball unplayable: ball is unavailable to be played by either team.

Infringements Penalty awarded against defender.

Penalty awarded against attacker.

Handling error by attacker.

Handling error by defender.

(Reason for infringement can also be captured).

Injury See injury in table 1.

$\begin{array}{ll}\text { Injured player } & \begin{array}{l}\text { Attacker. } \\ \text { Defender. }\end{array}\end{array}$

Not clear.

Injury location See injury location in table 1

integrated with video analysis. For example, observing an injury event using video is not straightforward. An injury in rugby is defined as 'Any physical complaint, which was caused by a transfer of energy that exceeded the body's ability to maintain its structural and/or functional integrity, that was sustained by a player during a rugby match or rugby training, irrespective of the need for medical attention or time-loss from rugby activities. An injury that results in a player receiving medical attention is referred to as a "medical-attention" injury and an injury that results in a player being unable to take a full part in future rugby training or match play as a "time-loss" injury". ${ }^{36}$ This definition is consistently used in rugby injury surveillance studies and requires access to the team or tournament. Injury surveillance data alone, however, do not provide enough detail to design and develop injury prevention programmes, especially if player behaviour or player technique is the target of an intervention. Therefore, 


\begin{tabular}{|c|c|}
\hline Descriptor & Definitions \\
\hline Scrum 28 & $\begin{array}{l}\text { A scrum is formed in the field of play when eight players from each team, } \\
\text { bound together in three rows for each team, engage with their opponents so } \\
\text { that the heads of the front rows are interlocked. } \\
\text { Scrum engagement occurs when the front-row of each team make contact } \\
\text { with each other. }\end{array}$ \\
\hline Frequency of scrum & Count of scrum events during match play. \\
\hline $\begin{array}{l}\text { Frequency of engagement } \\
\text { attempts }\end{array}$ & $\begin{array}{l}\text { Count of engagements and re-engagements (resets) before the scrum was } \\
\text { considered contestable. }\end{array}$ \\
\hline $\begin{array}{l}\text { Duration of (re-) } \\
\text { engagement (reset) }\end{array}$ & $\begin{array}{l}\text { The time (in minutes:seconds) from the engagement to when the whistle is } \\
\text { blown to reset the scrum. }\end{array}$ \\
\hline $\begin{array}{l}\text { Duration of contestable } \\
\text { scrum }\end{array}$ & $\begin{array}{l}\text { The time (in minutes:seconds) from the engagement to when the ball is } \\
\text { played. }\end{array}$ \\
\hline \multicolumn{2}{|l|}{ Scrum outcomes } \\
\hline $\begin{array}{l}\text { Scrum result (for complete } \\
\text { scrums) }\end{array}$ & $\begin{array}{l}\text { Attacking team retains the ball: attacking team maintains possession of } \\
\text { the ball after the scrum contest. } \\
\text { Defending team gains the ball: attacking team fails to maintain } \\
\text { possession of the ball after the scrum contest. }\end{array}$ \\
\hline Infringements & $\begin{array}{l}\text { Penalty awarded against attacking team. } \\
\text { Penalty awarded against defending team. } \\
\text { Free-kick awarded against attacking team. } \\
\text { Free-kick awarded against defending team. } \\
\text { Penalty type }{ }^{28} \text {. } \\
\text { Popping: intentionally lifting an opponent off their feet or forcing them } \\
\text { upwards out of the scrum. } \\
\text { Collapsing: deliberately collapsing a scrum. } \\
\text { Falling: deliberately falling or kneeling. } \\
\text { Pulling: pulling an opponent. } \\
\text { Intentional wheeling: deliberately wheeling the scrum. }\end{array}$ \\
\hline Injury & See injury in table 1. \\
\hline Injured player & See injured player in table 2 . \\
\hline Injury location & See injury location in table 1. \\
\hline
\end{tabular}

\begin{tabular}{|c|c|}
\hline Descriptor & Definitions \\
\hline $\begin{array}{l}\text { Line-outs and quick } \\
\text { line-outs }{ }^{28}\end{array}$ & $\begin{array}{l}\text { A lineout is formed on the mark of touch. Each team forms a single line parallel } \\
\text { to and half a metre from the mark of touch on their side of the lineout between } \\
\text { the } 5 \mathrm{~m} \text { and } 15 \mathrm{~m} \text { lines. A minimum of two players from each team are required } \\
\text { to form a lineout. } \\
\text { A quick line-out (quick throw) can take place before a line-out is formed and } \\
\text { is observed when a player whose feet are both outside the field of play throws } \\
\text { the ball parallel to or towards the thrower's own goal line, between the mark of } \\
\text { touch and the thrower's own goal line, so that it reaches the } 5 \mathrm{~m} \text { line before it } \\
\text { touches the ground or makes contact with a player. }\end{array}$ \\
\hline $\begin{array}{l}\text { Frequency of line-out } \\
\text { events }\end{array}$ & Count of line-out events during match play. \\
\hline $\begin{array}{l}\text { Number of players in } \\
\text { the line-out }\end{array}$ & Number of attackers and defenders in the formed line-out. \\
\hline Ball Thrown & $\begin{array}{l}\text { Short: ball is thrown to the first third of players in the line-out. } \\
\text { Mid: ball is thrown to the second third of players in the line-out. } \\
\text { Long: ball is thrown to the last third of players in the line-out. }\end{array}$ \\
\hline \multicolumn{2}{|l|}{ Line-out outcome } \\
\hline Line-out result & $\begin{array}{l}\text { Attacking team retains the ball: attacking team maintains possession of the } \\
\text { ball after the line-out contest. } \\
\text { Defending team gains the ball: attacking team fails to maintain possession of } \\
\text { the ball after the line-out contest. }\end{array}$ \\
\hline Post line-out event & $\begin{array}{l}\text { Maul: when a ball-carrier and at least one player from each team, bound } \\
\text { together and are on their feet. } \\
\text { Catch and drive: a player in the line-out catches the ball and moves towards } \\
\text { the opposition try-line } \\
\text { Distribute: a player in the line-out catches the ball and immediately passes the } \\
\text { ball to a team member. This can be accomplished from the top of the line-out or } \\
\text { after the player lands on their feet. } \\
\text { Line-out missed: players in the lineout did not receive the ball, either by } \\
\text { intentional overthrow or missed jumper. }\end{array}$ \\
\hline Infringements & $\begin{array}{l}\text { Penalty awarded against attacking team. } \\
\text { Penalty awarded against defending team. } \\
\text { Free-kick awarded against attacking team. } \\
\text { Free-kick awarded against defending team. } \\
\text { Scrum awarded to attacking team. } \\
\text { Scrum awarded to defending team. } \\
\text { (Reason for infringement can also be captured). }\end{array}$ \\
\hline Injury & See injury in table 1. \\
\hline Injured player & See injured player in table 2 . \\
\hline Injury location & See injury location in table 1. \\
\hline
\end{tabular}

\begin{tabular}{|c|c|}
\hline Descriptor & Definitions \\
\hline Maul $^{28}$ & $\begin{array}{l}\text { A maul begins when a player carrying the ball is held by one or more } \\
\text { opponents, and one or more of the ball-carrier's team mates bind on the } \\
\text { ball-carrier. A maul therefore consists, when it begins, of at least three } \\
\text { players, all on their feet; the ball-carrier and one player from each team. }\end{array}$ \\
\hline Frequency of mauls & Count of maul events during match play. \\
\hline Duration of maul & $\begin{array}{l}\text { Time (in minutes:seconds) from when the maul has formed to when the } \\
\text { ball is played. }\end{array}$ \\
\hline Number of attackers in maul & $\begin{array}{l}\text { Total number of players from the attacking team, including the player } \\
\text { carrying the ball in the maul, involved when the maul ended. }\end{array}$ \\
\hline $\begin{array}{l}\text { Number of defenders in } \\
\text { the maul }\end{array}$ & Number of players from the defending team. \\
\hline \multicolumn{2}{|l|}{ Maul outcomes } \\
\hline Maul result & $\begin{array}{l}\text { Attacking teams retains the ball: attacking team maintains possession } \\
\text { of the ball after the maul contest. } \\
\text { Defending team gains the ball: attacking team fails to maintain } \\
\text { possession of the ball after the maul contest. }\end{array}$ \\
\hline Infringements & $\begin{array}{l}\text { Penalty awarded against defender. } \\
\text { Penalty awarded against attacker. } \\
\text { Handling error by attacker. } \\
\text { Handling error by defender. }\end{array}$ \\
\hline Injury & See injury in table 1. \\
\hline Injured player & See injured player in table 2 . \\
\hline Injury location & See injury location in table 1. \\
\hline
\end{tabular}

video analysis should be integrated with injury surveillance data of the team or the tournament. Beyond understanding injury mechanisms and risk factors, ${ }^{56}$ video analysis can also be used to assess the effectiveness of an injury prevention intervention (be it a training programme or law change). Also, video analysis can be used to determine a change in on-field player behaviour and assist medical/referee decision making. For example, at the elite level, the Head Injury Assessment (HIA) is a process to manage the potentially serious sequelae of concussion. During the HIA process, video footage is available to the official match doctors to review and identify if any concussive signs and symptoms are apparent at the time of injury to decide whether to permanently remove the player from the match. ${ }^{8}$

Wearable microtechnology (eg, GPS) is a common feature in professional rugby union and has been successfully used to describe the physical demands of the sport. ${ }^{37}$ Like injury surveillance data, linking video analysis data to microtechnology data provides superior information compared with assessing the datasets in isolation. Microtechnology provides objective data of the physical demands. These data, along with standardised injury data and high-quality video analysis data will advance the integration of injury, video and microtechnology data within rugby. ${ }^{37}$

\section{Quality of video footage}

The quality of the video footage may have a direct impact on the quality of the analysis. ${ }^{34}$ At the professional level, televised matches provide good quality video, from different angles, with the main camera stable and at a suitable vantage point. At lower levels of rugby (eg, community level), video footage of matches is typically recorded using one camera with a less professional set-up. With limited resources available for video recording, onecamera angle may be sufficient for detailed analyses. Using one camera, recording should ideally take place on the half-way line at a height sufficient to capture the full field, with the camera mounted on a tripod for video stability. The ball should be kept at the centre of the camera view with a radius of approximately $10 \mathrm{~m}$. If more than one camera is available, the aim of the camera set up should be to increase the ability to distinguish body parts and players' on-the-ball and off-the-ball actions. Off-the-ball actions are particularly important for postconcussive analysis and HIA review. Related to the quality of the video footage, the 


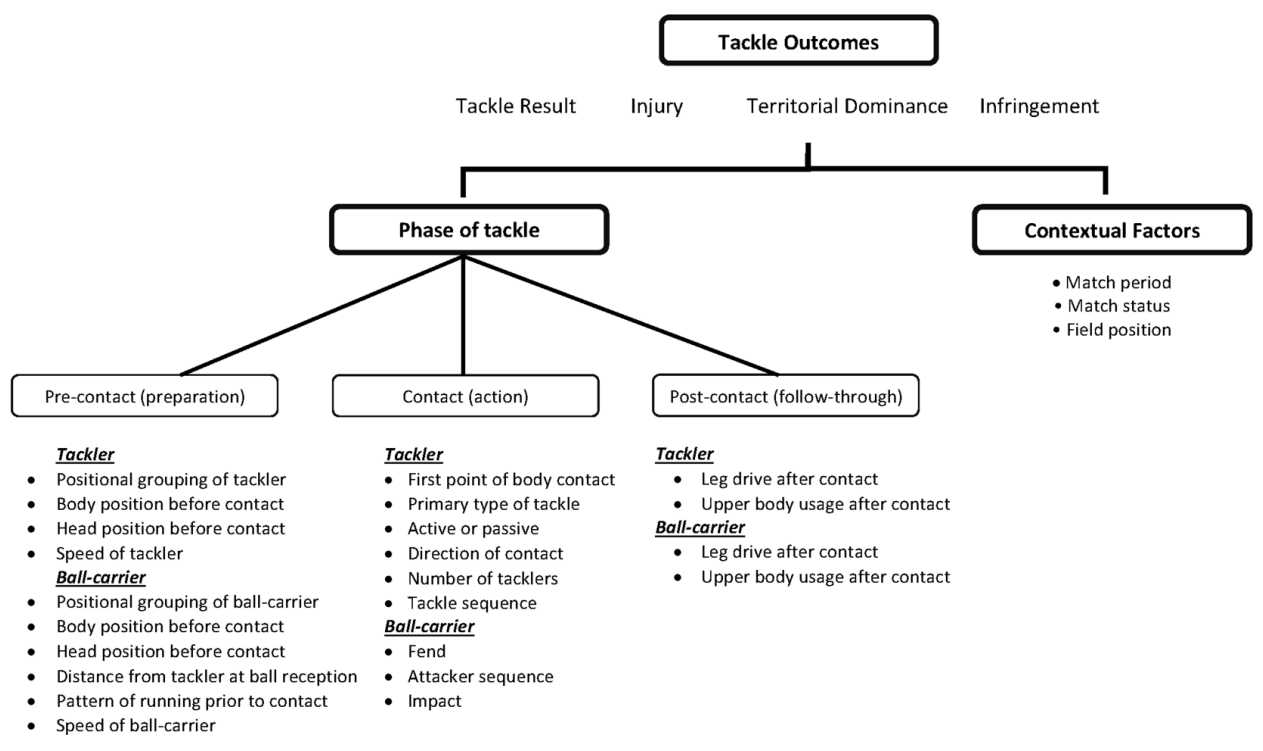

Figure 2 Video analysis model for the tackle.

software program used to analyse the video should also allow for control over the time lapse during each movement, as well as the recording and saving of each coded instance into a database. During the analysis, the analyst should be able to pause, rewind and watch the footage in slow motion or frame by frame.

\section{Technique measurements}

Another method to analyse rugby contact events is to score the technique of the player. ${ }^{2022}$ The score is based on a list of observable actions that represents the ideal form of the technique, which coaches use during training (online supplementary appendix 2). ${ }^{35} 38$ To score a player's technique, one point is awarded when an appropriate action is performed and zero when the action is not. The sum of these points represents the technical ability of the player. To date, this method has demonstrated encouraging construct validity by differentiating between injury and non-injury tackles, head impact tackles and successful tackles and shown to be stable across match quarters at the elite level. ${ }^{2022} 2439$ In this paper, we only provided technique criteria for the ball-carrier and tackler during the front-on tackle as an example; however, technique criteria for other types of tackles and contact events do exist. ${ }^{2022} 2439$

\section{What is already known}

- Video analysis research beyond the scope of performance has grown in the last 10 years.

- In video analysis studies, descriptors and definitions have either been lacking or inconsistent between studies.

- Video analysis can be linked to injury surveillance data and directly used as part of an injury prevention strategy.

\section{Dynamical systems}

From a dynamical systems perspective, video analysis can also be used to study the complex and dynamic movement interactions between players (within the same team and with the opposition) and the environment. ${ }^{240}$ For example, how spatial and temporal interactions emerge between players based on field location. ${ }^{40}$ Limited work has been done on video analysis in rugby matches from a dynamical systems perspective, particularly in understanding injury, which highlights an avenue for future research. Another avenue for future research is the video analysis of training sessions. An appreciable amount of work has been documented on the physical demands of training sessions ${ }^{41}{ }^{42}$; however, less is known about specific skill activities and coach behaviours during training. Systematic observation of rugby training sessions using video has a role to play in this regard. ${ }^{434}$

\section{Conclusion}

The aim of this consensus is to improve the consistency and quality of video analysis work in rugby union. The RUVAC group recommends using this consensus as the starting framework when conducting rugby video analysis research. Which variables to use (if not all) depends on the objectives of the study. Furthermore, the intention of this consensus is to help integrate video data with other data (eg, injury surveillance). This framework of descriptors and definitions can be used or developed further for other rugby football codes such as rugby sevens and rugby league.

\section{Author affiliations}

${ }^{1}$ Division of Exercise Science and Sports Medicine, Department of Human Biology, Faculty of Health Sciences, University of Cape Town, Cape Town, South Africa ${ }^{2}$ Institute for Sport, Physical Activity and Leisure, Centre for Sport Performance, School of Sport, Leeds Beckett University - Headingley Campus, Leeds, UK ${ }^{3}$ Carnegie Applied Rugby Research (CARR) Centre, Carnegie School of Sport, Leeds Beckett University, Leeds, United Kingdom

${ }^{4}$ Health, Physical Activity, Lifestyle and Sport Research Centre, Faculty of Health Sciences, University of Cape Town, Cape Town, South Africa

${ }^{5}$ Yorkshire Carnegie Rugby Union Football Club, Leeds, UK

${ }^{6}$ Leeds Rhinos RLFC, Leeds, United Kingdom

${ }^{7}$ Griffith Centre of Biomedical and Rehabilitation Engineering (GCORE), Menzies Health Institute Queensland, Griffith University, Gold Coast, Queensland, Australia ${ }^{8}$ School of Allied Health Sciences, Griffith University, Gold Coast, Queensland, Australia

${ }^{9}$ Institute of Bone and Joint Research, Kölling Institute of Medical Research, University of Sydney, Sydney, New South Wales, Australia 
${ }^{10}$ Department for Health, University of Bath, Bath, UK

${ }^{11}$ School of Biomedical Sciences, University of Leeds, Leeds, UK

${ }^{12}$ Division Sports Medicine, Department Medicine, Albany, Albany Medical College, Albany, NY, United States

${ }^{13}$ Medical Services, Rugby Football Union, London, United Kingdom

${ }^{14}$ Department of Epidemiology and Population Health, London School of Hygiene and Tropical Medicine, London, United Kingdom

${ }^{15}$ Premiership Rugby, London, UK

${ }^{16}$ Waterfall Sports Orthopaedic Surgery, Netcare Waterfall Hospital, Midrand, South Africa

${ }^{17}$ Wits Institute for Sport and Health (WISH), Faculty of Health Sciences, University of the Witwatersrand, Johannesburg, South Africa

${ }^{18}$ Research Institute for Sport and Exercise Science, University of Canberra, Canberra, Australian Capital Territory, Australia

${ }^{19}$ Biokinetics, Exercise and Leisure Sciences, School of Health Sciences, University of KwaZulu-Natal, Durban, South Africa

${ }^{20}$ Russia Rugby Federation, Moscow, Russia

${ }^{21}$ Bath Rugby, Bath, United Kingdom

${ }^{22}$ Union Argentina de Rugby, Buenos Aires, Argentina

${ }^{23}$ Medical Department, South Africa Rugby Union, Cape Town, South Africa

${ }^{24}$ High Performance, New Zealand Rugby, Wellington, New Zealand

${ }^{25}$ World Rugby, Dublin, Ireland

${ }^{26}$ School of Science and Technology, University of New England, Armidale, New South Wales, Australia

${ }^{27}$ England Performance Unit, The Rugby Football League, Leeds, United Kingdom

Twitter Sharief Hendricks@Sharief H, Kevin Till @KTConditioning, Steve den Hollander @steve_dh1, Simon Kemp @drsimonkemp, Jon Patricios @jonpatricios, Andy Rock@Rock_Andy1, Keith A Stokes @drkeithstokes, Kenneth L Quarrie @ kenquarrie and Ben Jones@23benjones

Contributors SH drafted the manuscript, and all other authors provided input to prepare the manuscript for publication. SdH conducted the literature search for the review.

Funding The authors have not declared a specific grant for this research from any funding agency in the public, commercial or not-for-profit sectors.

Competing interests None declared.

Patient consent for publication Not required.

Provenance and peer review Not commissioned; externally peer reviewed.

Data availability statement No data are available.

ORCID iDs

Sharief Hendricks http://orcid.org/0000-0002-3416-6266

Kevin Till http://orcid.org/0000-0002-9686-0536

Trevor N Savage http://orcid.org/0000-0001-6608-8664

Simon Kemp http://orcid.org/0000-0002-3250-2713

Jon Patricios http://orcid.org/0000-0002-6829-4098

Keith A Stokes http://orcid.org/0000-0002-5049-2838

Kenneth L Quarrie http://orcid.org/0000-0003-1703-8489

Ross Tucker http://orcid.org/0000-0002-4294-4822

\section{REFERENCES}

1 McGarry T, O'Donoghue P, Sampaio J, et al. Routledge Handbook of sports performance analysis. London: Routledge, 2013.

2 Glazier PS. Game, set and match? Substantive issues and future directions in performance analysis. Sports Med 2010;40:625-34.

3 Hughes MD, Bartlett RM. The use of performance indicators in performance analysis. J Sports Sci 2002:20:739-54.

4 Verhagen E, Van Mechelen W. Sports injury research. Oxford: Oxford University Press, 2010

5 Bahr R, Krosshaug T. Understanding injury mechanisms: a key component of preventing injuries in sport. Br J Sports Med 2005:39:324-9.

6 Krosshaug T, Andersen TE, Olsen O-EO, et al. Research approaches to describe the mechanisms of injuries in sport: limitations and possibilities. Br I Sports Med 2005;39:330-9.

7 Fuller GW, Kemp SPT, Raftery M. The accuracy and reproducibility of video assessment in the pitch-side management of concussion in elite rugby. I Sci Med Sport 2017;20:246-9

8 Gardner AJ, Kohler R, McDonald W, et al. The use of sideline video review to facilitate management decisions following head trauma in Super Rugby. Sports Med Open 2018;4:20.

9 James N, Taylor J, Stanley S. Reliability procedures for categorical data in performance analysis. Int J Perform Anal Sport 2007:7:1-11.

10 O'Donoghue P. Reliability issues in performance analysis. Int J Perf Anal Sport 2007:7:35-48.
11 den Hollander $\mathrm{S}$, Jones $\mathrm{B}$, Lambert $\mathrm{M}$, et al. The what and how of video analysis research in rugby union: a critical review. Sports Med Open 2018;4:27.

12 Hendricks S, Lambert M. Tackling in rugby: coaching strategies for effective technique and injury prevention. Int J Sports Sci Coach 2010:5:117-35.

13 Quarrie KL, Hopkins WG. Tackle injuries in professional rugby union. Am I Sports Med 2008:36:1705-16.

14 Fuller CW, Ashton T, Brooks JHM, et al. Injury risks associated with tackling in rugby union. Br J Sports Med 2010:44:159-67.

15 Savage TN, McIntosh AS. Tackling reliability and construct validity: the systematic development of a qualitative protocol for skill and incident analysis. J Sports Sci 2017;35:449-56.

16 McIntosh AS, Savage TN, McCrory P, et al. Tackle characteristics and injury in a cross section of rugby union football. Med Sci Sports Exerc 2010;42:977-84.

17 Jones J, Hunter D. Consensus methods for medical and health services research. BMJ 1995;311:376

18 McMillan SS, King M, Tully MP. How to use the nominal group and Delphi techniques. Int J Clin Pharm 2016:38:655-62.

19 Burger N, Lambert MI, Viljoen W, et al. Mechanisms and factors associated with tackle-related injuries in South African youth rugby union players. Am I Sports Med 2016;0363546516677548.

20 Burger N, Lambert MI, Viljoen W, et al. Tackle technique and tackle-related injuries in high-level South African rugby Union under-18 players: real-match video analysis. $\mathrm{Br} J$ Sports Med 2016:50:932-8.

21 Hendricks S, Matthews B, Roode B, et al. Tackler characteristics associated with tackle performance in rugby union. Eur J Sport Sci 2014;14:753-62.

22 Hendricks S, O'connor S, Lambert M, et al. Contact technique and concussions in the South African under-18 Coca-Cola Craven week rugby tournament. Eur J Sport Sci 2015:15:557-64

23 Hendricks S, van Niekerk T, Sin DW, et al. Technical determinants of tackle and ruck performance in international rugby union. J Sports Sci 2018;36:522-8.

24 Tierney GJ, Denvir K, Farrell G, et al. Does player time-in-game affect tackle technique in elite level rugby union? J Sci Med Sport 2017;1:221-5.

25 Wheeler K, Sayers M. Contact skills predicting tackle-breaks in rugby union. Int J Sports Sci Coach 2009:4:535-44.

26 Wheeler KW, Askew CD, Sayers MG. Effective attacking strategies in rugby union. Eur J Sport Sci 2010;10:237-42.

27 Wheeler KW, Mills D, Lyons K, et al. Effective defensive strategies at the ruck contest in rugby union. Int I Sports Sci Coach 2013;8:481-92.

28 World Rugby. Laws of the game Rugby Union, 2018. Available: http://laws. worldrugby.org/?language $=$ en

29 Smyth G, O'Donoghue P, Wallace E. Notational analysis of contact situations in rugby union. Notational Analysis of Sport IV Cardiff: UWIC, 1998: 156-64.

30 Hendricks S, O'Connor S, Lambert M, et al. Video analysis of concussion injury mechanism in under-18 rugby. BMJ Open Sport Exerc Med 2016;2:e000053.

31 Sewry N, Lambert M, Roode B, et al. The relationship between playing situation, defence and tackle technique in rugby union. Int I Sports Sci Coach 2015:10:1115-28.

32 Tierney GJ. A biomechanical assessment of direct and inertial head loading in rugby union. PhD thesis. Trinity College, 2018.

33 Chow JW, Knudson DV. Use of deterministic models in sports and exercise biomechanics research. Sports Biomech 2011;10:219-33.

34 Knudson DV. Qualitative diagnosis of human movement: improving performance in sport and exercise. Champaign: Human Kinetics, 2013.

35 Lees A. Technique analysis in sports: a critical review. J Sports Sci 2002;20:813-28.

36 Fuller CW, Molloy MG, Bagate C, et al. Consensus statement on injury definitions and data collection procedures for studies of injuries in rugby union. Br J Sports Med 2007:41:328-31

37 Whitehead S, Till K, Weaving D, et al. The use of microtechnology to quantify the peak match demands of the football codes: a systematic review. Sports Med 2018:1-27.

38 Knudson DV, Morrison CS. Qualitative analysis of human movement. Champaign: Human Kinetics, 2002.

39 Davidow D, Quarrie K, Viljoen W, et al. Tackle technique of rugby union players during head impact tackles compared to injury free tackles. J Sci Med Sport 2018;21:1025-31.

40 Vilar L, Araújo D, Davids K, et al. The role of ecological dynamics in analysing performance in team sports. Sports Med 2012;42:1-10.

41 Weaving D, Dalton NE, Black C, et al. The same story or a unique novel? Within-participant principal-component analysis of measures of training load in professional rugby union skills training. Int I Sports Physiol Perform 2018;13:1175-81.

42 Weaving $D$, Jones B, Marshall P, et al. Multiple measures are needed to quantify training loads in professional rugby league. Int I Sports Med 2017;38:735-40.

43 Cope E, Partington M, Harvey S. A review of the use of a systematic observation method in coaching research between 1997 and 2016. J Sports Sci 2017:35:2042-50.

44 Kerr HA, Ledet EH, Ata A, et al. Does instructional video footage improve tackle technique? Int J Sports Sci Coach 2018;13:3-15. 